\title{
A community study on the relationship between stress, coping, affective dispositions and periodontal attachment loss
}

\author{
Sam K. S. $\mathrm{Ng}^{1,2}$, W. Keung Leung ${ }^{1}$ \\ ${ }^{1}$ Faculty of Dentistry, The University of Hong Kong, ${ }^{2}$ Department of Psychiatry, Tuen Mun \\ Hospital, Hong Kong SAR, China,
}

Running Title: Stress and periodontal status

Corresponding author

W. Keung Leung

Faculty of Dentistry, The University of Hong Kong, Room 3B39, Prince Philip Dental

Hospital, 34 Hospital Road, Hong Kong SAR, China

Tel: +852-2859-0417

Fax: $+852-2858-7874$

E-mail: ewkleung@,hkucc.hku.hk 
$\mathrm{Ng}$ SKS, Leung WK: A community study on the relationship between stress, coping, affective dispositions and periodontal attachment loss. Community Dent Oral Epidemiol

Abstract - Psychological factors may increase the risk for periodontal diseases. Contemporary conceptualization of the stress process supports the evaluation of stress at three levels: stressors, moderating and mediating factors, and stress reactions. Objective: This study was to investigate the relationship of periodontal disease in terms of clinical attachment level (CAL) to psychosocial stress, making reference to the major components of stress process. Methods: A cross-sectional study of 1,000 subjects aged 25 to 64 years in Hong Kong was conducted. Subjects were asked to complete a set of questionnaires measuring stressors including changes, significant life event and daily strains, stress reactions including physiological and affective responses, and coping and affective dispositions. CAL was assessed. Results: Individuals with high mean CAL values had higher scores on the job and financial strain scales than periodontally healthy individuals $(P<0.05)$, after adjusting for age, gender, cigarette smoking and systemic disease. Depression, anxiety trait, depression trait, problem-focused coping, and emotion-focused coping were also related to CAL. Logistic regression analysis indicated that all these factors were significant risk indicators for periodontal attachment loss, except problem-focused coping, which reduced the odds of CAL. Individuals who were high emotion-focused copers, low problem-focused copers, trait 
anxious, or trait depressive had a higher odds of more severe CAL. Conclusion: Chronic job and financial strains, depression, inadequate coping, and maladaptive trait dispositions are significant risk indicators for periodontal attachment loss. Adequate coping and adaptive trait dispositions, evidenced as high problem-focused coping and low anxiety/depression trait, may reduce the stress-associated odds.

Key words: coping, periodontal disease, psychology, stress, trait.

Address

W. Keung Leung

Faculty of Dentistry, The University of Hong Kong, Room 3B39, Prince Philip Dental Hospital, 34 Hospital Road, Hong Kong SAR, China

Tel: $+852-2859-0417$

Fax: $+852-2858-7874$

E-mail: ewkleung@,hkucc.hku.hk 
Periodontal diseases refer to chronic inflammatory conditions caused by subgingival bacteria. The aetio-pathogenicity of chronic inflammatory periodontal diseases is complex. Many processes are at work, and no single one alone could be used to satisfactorily explain the tissue destruction phenomenon (1). Studies have suggested the aetiological significance of specific pathogenic bacteria, plaque accumulation, diabetes mellitus, age, gender and cigarette smoking $(2,3)$. A significant portion of variation in disease severity (variance in statistical term) however cannot be explained with only these factors (4). The possible association between psychological factors and inflammatory periodontal diseases has become the subject of many studies $(5,6)$.

Reports on the impacts of psychosocial factors on general health status of an individual were available some years ago $(7,8)$. Psychological factors were suspected to be capable of increasing the risk for periodontal diseases and were investigated in a number of studies in past few decades. The earlier studies were predominantly focused on the relationship between stressful life situations and necrotizing periodontal diseases (9). Most of those studies involved a small number of subjects, and only a few reported the relationship between psychosocial factors and periodontal health $(5,10,11)$. Green and co-workers first reported the systematic evaluation of life events stress with self-reported measures and periodontal disease including gingivitis and periodontitis. A significant correlation was found between life events stress and periodontal status (10).

Marcenes and Sheiham (5) carried out a study on oral health status and work stress in Belo Horizonte, Brazil. A significant association was found between poor periodontal status and high work mental demand and low marital quality. Marcenes et al. (12) then reported significant association between marital or family problems and oral symptoms, after adjustment for other variables. Freeman and Goss (11) also revealed significant correlation between occupational stress and type-A personality with increased pocket depth.

The Erie County Risk Factor Study $(2,3,6,13)$ was among one of the most extensive 
and systematic series of studies conducted exploring the relationship between stress, distress, and coping behavirours with periodontal disease. It was found that financial strain and state of depression are significant risk indicators for more severe periodontal disease after adjustment for gender, smoking and diabetes mellitus, and stress response moderating factor like adequate coping may reduce the stress-associated odds. The study, however, did not investigate the relationship between the other stress response moderating factors such as personality traits/dispositions and periodontal disease in the cohorts studied. Personality traits/dispositions were considered to be important factors regarding stress response moderation (14). A later study by Teng et al. (15) also showed that psychological well being and smoking are significantly associated with chronic periodontitis.

The impact of stress on the immune system has been well researched and reasonably established. There are many reports suggesting that psychological stress may down-regulate the periodontal cellular immune response $(9,11,13)$. Psycho-neuro-immunological (PNI) studies provided further molecular- and cellular-based evidences regarding the association between immunologic functioning and stressful life events, negative affective states (e.g. anxiety, depression, anger), and psychological vulnerability (16). PNI intervention studies focused on manipulation of the latter factors demonstrated that the outcome immune responses were suppressed by stress (17).

In summary, findings from preliminary studies supported the existence of a positive correlation between psychological stress and periodontal disease (18, review). Many of these studies however attempted to investigate and evaluate only some individual psychological variables in the stress process, and/or the sample size was limited leading to inconsistence in the findings and rendered the results inconclusive in making generalizable statements.

Contemporary conceptualization of the stress process supports the evaluation of stress at three levels: stressors, moderating and mediating factors, and stress reactions $(14,19)$. It emphasizes the appraisal process and the unity of stress, emotions (such as anxiety and 
depression), and coping. Stress responses would be determined primarily by the appraisal process that makes personalized perceptions of a stressor or threat, which in turn is influenced by factors including personality trait, coping strategies, experience and reference information. The factor of personality trait is generally considered as a major moderating factor. Physiological response including autonomic arousal, hormonal fluctuations, and neurochemical changes so aroused would interact with affective response. Behavioural response in coping with the stressor such as lashing out on others or seeking help may lead to different reciprocal response from the outside world, and modulate the emotions and physiological status, making it more stressful or less. This spontaneously affects the impact of the stressor, and subsequent appraisal, coping, and stress responses. Stress accordingly should be evaluated as a dynamic and interactional process of intricate systems with formulations and operationalization of the components at various levels (19).

The aim of this study was to investigate the relationship of periodontal disease to psychosocial stress, making reference to the major components of the stress process including stressor, mediating and moderating factors (coping strategies and traits), and stress responses (psychological and somatic responses) based on the contemporary understanding of stress process $(14,19)$. Periodontal disease was assessed by probing pocket depth (PPD) and clinical attachment level (CAL). Psychological questionnaires were used to assess life stressors, coping, trait, psychological and somatic stress responses.

\section{Materials and methods}

\section{Subjects}

Recruitment of subjects was designed to accomplish two objectives. Firstly, a large population based cross-sectional sample was designed to display broad variation in periodontal condition and in potential risk indicators to allow an adequate assessment of the relationship between explanatory and outcome variables. Secondly, effort was paid to 
ascertain the generalizability of the findings of this study to a broader population.

Three general dental practices were selected for conduction of the study, one in each of the three main geographic districts of Hong Kong. Patients who presented for treatment in these clinics were invited to participate in the study. Subjects were also recruited through advertisement posted in these clinics. The target sample size was 1,000 and the subject selection criteria included: 1) within the age range of 25 to 64 years; 2) not edentulous; and 3) no psychiatric history nor requiring antibiotic prophylaxis cover for clinical periodontal examination. A total of 1,266 subjects were approached. Of these 226 did not consent to participate and 40 were excluded for incompatibility with selection criteria. Recruitment period lasted for nine months.

A total of 1,000 subjects (531 females and 469 males), between the age of 25 and 64 years $(41.3 \pm 10.5$ years $)$, participated in this study. More than one-third of the subjects (35.5\%) were between the age of 35 to 44 ; the smallest sector was being the group of age 55 to $64(12 \%)$.

\section{Procedures}

The research team for the study consisted of the first author as principal investigator dentist, two dental surgery assistants and two interviewers. A panel was set up for supervising the research project, including two dentists, two psychologists and one statistician specializing in health survey studies.

Training was provided to the two dental surgery assistants in introducing the research project and recording the clinical data. The psychological questionnaires were issued by two trained interviewers who were not involved in any future assessment and analysis. Two final year psychology undergraduates, fluent in both Chinese and English, from The University of Hong Kong were recruited to be the interviewers and trained to assist in administration of the psychological questionnaires. Data set from each subject was input twice independently by 
the two interviewers and any discrepancy was then clarified.

During the appointment, the trained interviewer first explained the details of the research project to participants individually. Patients who agreed to participate were asked to read and then signed an informed consent. Subjects were asked to complete a questionnaire including the following sections: 1) demographic and socio-economic details; 2) medical history reporting symptom and diagnosed systemic diseases; 3) dental habits and dental care utilization; and 4) history of cigarette smoking and exposure to occupational hazards. Tobacco consumption history was categorized as per Grossi et al. (2).

All participants were checked and confirmed by the investigator dentist who was also a qualified clinical psychologist before the clinical examination that they had no relevant medical history requiring prophylactic antibiotic cover and had no positive psychiatric history. Periodontal examination was then carried out. When clinical examinations were completed, a brief verbal report of dental status was given to the subject including indications for treatment in accordance with the standard professional ethical requirements.

Subjects were then given a set of self-administered psychological questionnaires in a face-to-face interview with one of the trained interviewers. Instructions were explained and subjects were arranged to complete the questionnaires in a private setting in the clinic. The interviewer was standby to clarify any queries arising during completion of the questionnaires. All the questionnaires were designed in self-administered format. For those illiterate or marginally literate subjects, who were mainly from the older age groups, their questionnaires were completed in an interviewer assisted format.

Upon completion of the psychological questionnaires, participants were invited to describe their feelings and comment on what they had experienced through the course of the study procedures, including clinical examination and questionnaires survey.

\section{Periodontal Examination}


Clinical examination included recording the number of standing teeth; measurement of the following parameters at six sites on each tooth: calculus $(\mathrm{Cl}$, visible or detectable through tactile sense using a periodontal probe), bleeding on probing (BOP), followed by recession (REC) and probing pocket depth (PPD) after dental prophylaxis (20). Tooth-sites excluded from the examination were impacted teeth, retained roots, grossly broken down teeth or teeth which were difficult to examine due to inaccessibility of the sites or had the cemento-enamel junction (CEJ) indeterminable on clinical examination. Brockprobe periodontal probe* was used, which gives approximately a calibrated 20 gram force for measurement of $\mathrm{Cl}$, BOP, REC, and PPD. The measurement of REC, PPD and clinical attachment level (CAL) was done according to Pilgram et al. (20) with modification: REC was measured from the CEJ to the gingival margin, with a positive value if there was recession and a negative value in the absence of recession; CAL was calculated by summation of PPD and REC.

\section{Psychological instruments}

Three psychological instruments were used in assessment of stressor in the subjects' daily living. The Life Event Questionnaire (LEQ) (21) is a 12-item instrument measuring common life events that tend to be perceived as threatening. The Social Readjustment Rating Scale (SRRS) $(22,23)$ assesses a wide range of stressful experience in life changes. The scale assigns numerical values to 43 major life events. These values are supposed to reflect the magnitude of the readjustment required by each change. The Measure of Chronic Stress adapted from the Problems of Everyday Living Scale of Pearlin and Schooler (24). The scale was developed with the appraisal of stress from sociological perspective $(25,26)$. It assesses chronic stressors associated with the central roles of people in daily life. These include worker, financial manager, spouse and parent. All these psychological instruments had been

\footnotetext{
* Brokeprobe periodontal probes come with Williams markings and indicator of probing pressure of 20 grams, +/- 2 grams. (Prockport Industries, N.J., USA)
} 
validated for use in a Chinese population $(27,28)$.

Two psychological instruments were used in assessment of the subjects' stress response. The Symptom Checklist - 90 (SCL-90) (29) is a multidimensional self-report inventory of 90 items designed to screen for a broad range of psychological problems and symptoms of psychopathology, including somatization, obsessive-compulsive, interpersonal sensitivity, depression, anxiety, hostility, phobic sensitivity, paranoid ideation and psychoticism. The Depression Anxiety Stress Scales - State (DASS-S) (30, 31) Chinese short version (32) is used to measure the affective responses of an individual in face of stress. It is composed of three scales: anxiety, depression, and stress, each consisting of 7 items.

Two psychological instruments were used in assessment of subjects' coping and trait dispositions. The COPE Inventory (COPE) $(28,33)$ is used to measure the coping styles and strategies. The "dispositional" brief version is used in this study. It consists of 28 items measuring 14 different coping behaviours each with two pairs of polar-opposite tendencies. Depression Anxiety Stress Scales - Trait (DASS-T) $(30,32,34)$ Chinese version (32) is used to assess the trait predispositions of depression, anxiety and stress of the subjects. It consists of 42 items, with 14 items for each scale of depression, anxiety and stress.

\section{Data analysis}

Descriptive analysis was conducted to describe the demographic characteristics of subjects, the pattern of dental habits and dental service utilization, and periodontal status. After being used to calculate CAL, negative REC values were transformed to ' 0 ' before further relevant data analysis. Full mouth mean CAL was stratified into 5 ordered categories as described by Genco et al. (6). Weighted Kappa statistics was employed to examine the reliability of measurements during periodontal examination - the examination was repeated in a randomly selected quadrant in every tenth subjects. Calibration was repeated back in the Periodontology Clinic, Dental Faculty, The University of Hong Kong after every one hundred 
subjects were examined.

The validity of the collected psychological data from the study sample was examined by assessing the internal consistency of items within each subscale or individual psychological instrument, the item-scale correlation and the correlation between subscales. Cronbach's alpha and correlation coefficient were utilized accordingly for these purposes. In analyses of coping styles and strategies, as suggested by the developer of the COPE scales (33), factor analysis with Varimax rotation technique was conducted to extract a set of second-order factors of coping strategies as predictor variables in subsequent analysis.

Clinical attachment levels were dichotomized into 2 groups for odds assessment: combining healthy and low CAL categories as group " 0 " (minimal disease) and combining high and severe CAL categories as group "1" (high/severe CAL). Ordinal logistic regression models were then used to evaluate the association of the outcome variables, namely clinical attachment level (CAL) and other explanatory variables. Age was first entered into the regression model because of its known strong association with attachment loss. Systemic disease e.g. diabetes, allergy and anemia was also entered independently into the logistic model. Variables of significance level of 0.10 or less were then entered into the regression model in a stepwise approach. Odds ratios (O.R.) and the corresponding 95\% confidence intervals (C.I.) were calculated.

To further examine the detailed picture of the odds of periodontal attachment loss due to the interaction of the stressors on one hand and the dispositional constructs of coping behaviours and personality traits on the other, median split of relevant scores (35) was conducted to stratify subjects of groups " 0 " and " 1 " disease affected as a whole into "high" and "low" groups of problem-focused copers, emotion-focused copers, trait anxious subjects and trait depressive subjects respectively. All analyses were conducted using SPSS (Version $11.5,2004)$ for Windows. Significance level of 0.05 was adopted and post-hoc comparisons were performed using the Tukey's HSD test. 


\section{Ethics}

The Ethics Committee of the Faculty of Dentistry, the University of Hong Kong approved the study. All participants volunteered themselves to participate and all received comprehensive information on the study.

\section{Results}

The subjects surveyed were predominantly Chinese (95.5\%). Over half of the subjects were either married or lived with partner (55\%). Over two-thirds $(74.9 \%)$ of the respondents had secondary or above education. All could read Chinese except that 38 illiterate subjects required substantial assistance from the interviewers. Approximately $60 \%$ of the respondents had monthly household incomes more than $\$ 10,000$ (in Hong Kong Dollars, USD $\$ 1.00=$ HKD \$7.80) (Table 1). A summary of frequency of reported systemic diseases, smoking habits and drinking habits, and exposure to occupational hazards is shown in Table 2.

Table 3 summarized the data of number of teeth present, mean BOP, mean $\mathrm{Cl}$, and mean CAL. The distribution of subjects according to probing depth, recession and clinical attachment levels is shown in Table 4. The intra-examiner reproducibility of clinical periodontal examination results expressed as proportion of agreement was never lower than $83 \%$. The Kappa statistic was good to very good (weighted Kappa $=0.67-0.89$ ) regarding the various periodontal parameters measured.

Table 5 shows the results of evaluation of validity of various psychological instruments used in the present study. The Cronbach's alpha ranged from 0.79 to 0.97 for the individual scales and subscales. The item-scale correlation coefficients ranged from 0.65 to 0.93 with various subscales of the Daily Strains, SCL-90, DASS-S, and DASS-T, from 0.51 to 0.79 with the role strain composite scale. The discriminant validity was measured by the correlation with other subscales. It ranged from 0.07 to 0.22 for various subscales of the 
Daily Strains, with the exception that the correlation coefficient between job and financial strain scores was $0.41(P<0.05)$, and ranged from 0.08 to 0.23 for the composite scale with various subscales. It ranged from 0.11 to 0.24 for the SCL-90, from 0.29 to 0.34 for the DASS-S, and from 0.29 to 0.36 for the DASS-T.

Factor analysis using Varimax rotation was carried out to extract the second-order factors from among the COPE scales as suggested by Carver et al. (33) so as to determine the composition of the higher-order factors in this population. A total of three factors were obtained accounting for $73.2 \%$ of the total variance, namely 1) "Problem-focus coping", 2) "Emotion-focused coping", and 3) "Less adaptive coping" (Table 6). The factor loadings on factors 1 and 2 were all above 0.7 while that on factor 3 were above 0.4 . These patterns of relationships suggested that the items in individual factors clustered together with reasonably high correlation.

The mean scores of the various psychosocial measurements after adjusting for the effects of age, gender and smoking are shown for different severities of clinical attachment level in Table 7. In assessment of chronic daily strains with Measure of Chronic Stress, statistically significant differences were detected in job, financial and role strain composite scores across the various CAL categories. Subjects with more severe CAL had higher job, financial and role strain composite scores than the periodontally healthy subjects. Post hoc tests revealed that, for these three scales, the scores in the severe CAL group was significantly higher then that of the healthy to high severity groups.

For measurement of stress response, statistical significant difference was detected in the means scores of "Depression" subscales of both the SCL-90 and the DASS-S. Subjects in the more severe CAL group had depression score higher than the periodontally healthy subjects. Among the psychosocial instruments measuring trait dispositions and coping behaviours, statistical significant difference were detected in "Depression trait" and "Anxiety trait" subscales of DASS-T, "Problem-focused coping" and "Emotion-focused coping" of COPE. 
Statistical analysis failed to detect any significant correlation between scores of LEQ and SRRS with CAL, nor between number of teeth present, Cl, BOP, REC, PPD, and the various psychological factors.

The results of the ordinal logistic regression are shown in Table 8 (group " 0 " = minimal disease, i.e. healthy/low CAL categories, group "1" = high/severe CAL categories). Males had higher odds for high/severe CAL than females. Age was positively associated with high/severe CAL, when older age groups were compared to the younger age group of 25 to 34 years old. Education was inversely associated with high/severe CAL. For subjects with a history of diabetes, the odds for high/severe CAL was more than twice that of subjects who did not have diabetes. The odds for high/severe CAL in smokers increased with increasing amounts of smoking. Other systemic diseases, occupational hazards and drinking habits were not significant variables in the model.

High/severe CAL status was significantly associated with job strain, financial strain and depression. Trait depression and trait anxiety were found associated with high/severe CAL. Problem-focused coping was significantly and inversely associated with high/severe CAL whereas emotion-focused coping was significantly associated with high/severe CAL category.

Subjects were stratified by median-split (35) in accordance with their coping styles and trait dispositions to further assess the risk differential for minimal disease versus high/severe CAL between subjects with "high" and "low" problem-focused coping, emotion-focused coping, depression disposition and anxiety disposition (Table 9). Statistical significant differences between "high" and "low" level groups were detected in the respective disposition and coping variables after the median-split stratification $(P<0.05)$.

Results of analysis of ordinal logistic regression according to the various dichotomized variables, controlling for age, gender and smoking, presenting the interaction of trait dispositions and coping styles, with job and financial strains in odds evaluation of periodontal 
attachment loss is shown in Table 10. It can be seen that the odds for high/severe CAL for the subgroup of 767 subjects is greater in those with high levels of job strain or financial strain. Those scoring high on trait depression, trait anxiety or emotional-focused coping (poor coping), or those scoring low on problem-focused coping (good coping) are at even greater odds for periodontal destruction. On the contrary, subjects scoring low on trait depression, trait anxiety or emotion-focused coping (poor coping), or scoring high on problem-focused coping (good coping) are at no more odds for periodontal attachment loss than those who report little or no job strain or financial strain.

\section{Discussion}

The sample in the present study, within the limitation of available resources, achieved a reasonable size comparable with similar studies in evaluation of periodontal status (c.f. 6,38 ). Qualitatively, the study sample also appeared satisfactory when compared to data describing the demographic characteristics and periodontal status profile of local population (36-38) (Tables 1 and 3). Seventy five percent of the subjects reported that they had not visited a dentist for at least a year, except to seek treatment for a specific dental problem. This indicated that most of the individuals surveyed were non-regular attenders, which was in line with what was observed earlier in the Hong Kong population (39). The size of various sub-samples, number of subjects in categorized or dichotomized sub-groups, remained adequate and sufficient for further statistical analysis (40). Full mouth mean CAL was employed as estimation of the historical amount of periodontal destruction in a given patient in the present study (41). Similar to many other studies, high/severe full mouth mean CAL was associated with smoking, increasing age, diabetes mellitus, and gender, while higher education status is associated with better periodontal status $(6,9)$.

Since analyses of predictor variables and subsequent interpretations and conclusions are based on self-reported psychosocial traits, the goodness of fit of the collected data of our 
study population to the hypothetical factor structures of the various psychological instruments used was of crucial importance. However, it was difficult and often impossible to reproduce the exact factor structures of the original instruments. Nevertheless, Cronbach coefficients of all sub-scales of the instruments in the present study were high (Table 5). In fact, the lowest Cronbach recorded was 0.79 , from the Being Single subscale of the Measure of Chronic Stress (Daily Strains) while the high Cronbach alphas obtained from the 9 subscales of the SCL-90 were all more than 0.85 indicating that the data collected from the dimensions used were quite reliable. The discriminant validity of the measures was primarily supported by the relatively low correlation between the subscales (Table 5). The validity of the instruments used was also empirically supported as the results were comparable with the local norms $(28$, $32,42,43)$. The issue of cultural specificity of coping behaviours $(14,33,44)$ was addressed with exploration of factor structures of the study population by factor analysis as suggested by Carver et al. (33). (Table 6)

Job and financial strain were associated with severe attachment loss categories (Table 7). These two particular measures evaluate the role of an individual as worker and as financial manager. The questions asked assess chronic and long-term status rather than transient and acute stress. Examples of these questions are: Do you have more work than you can handle? Do you work too many hours? Is the income I earn just about right for the job I have? Can I count on a steady income? At the present time are you able to afford a home that is large enough? How often does it happen that you don't have enough money to afford the leisure activities that you/your family want(s)? These questions likely elicit a response representative of chronic, persistent and long-term daily strain with the concomitant of long lasting and chronic stress. Gardell (45) suggested that important job stressors include high mental demands, excessive work and time pressure, under-stimulation, under-utilization of skills, and lack of novelty. All these were included in the job-related questions employed in the present study. Dorian et al. (46) demonstrated in a study of chronic work stress in accountants 
that their immunological defense was increased at the time of peak stress, followed by immunosuppression during the post-stress period as reflected in the immunologic parameters regarding interleukin generation, interleukin responsiveness, natural killer cell activity, and lymphocyte reactivity to phyto-haemagglutinin. In summary, this chronic stress may lead to adverse effects on immune response and reduce resistance to pathogens, including those causing the chronic periodontal inflammation. That may explain the observed association between job strain and increased periodontal attachment loss.

A moderate correlation was found between job strain and financial strain $(\mathrm{r}=0.41, P<$ 0.05) (Table 5). This statistical co-linearity may be explained by the job attitude and the social characteristics of the Hong Kong population. Surveys in 2004 revealed that Hong Kong, well-known for its capitalistic context and persistently the highest rating worldwide for economic freedom, was the fifth most expensive city with respect to cost of living and at the sixth position on the world competitiveness scoreboard (47-49). The pressure and stress of maintaining the living in such context is tremendous; and, people are used to consider the utility purpose of job as of paramount importance in their life. Financial and material rewards from job are usually carefully evaluated, while issues of interest and aptitude are usually assigned less significant rating. Thus the current research group was not surprised finding that the job and finance strains were associated closely together.

Stress as measured by LEQ and SRRS, for stressors of less chronic nature, was not found to have any significant correlation with CAL and other periodontal parameters. These observations appeared consistent with the nature of periodontal disease of being a chronic and usually slow progressing inflammatory disease. In contrast to some of the previous studies $(10,13,15,50-56)$ which had attempted to investigate individual psychological variables in the stress process, and/or with limited sample size suggesting a positive association between acute stressor(s) and periodontal status, the present findings remained consistent with an earlier population study with the inclusion of the systematic variables of 
the stress process (6).

The odds of suffering from more severe clinical attachment loss was associated with emotion-focused coping while the reverse was true for problem-focused coping (Table 8). Coping has to do with the way people manage life conditions that are stressful. Emotion-focused coping aims at managing the emotions tied to the stressful situation without changing it, while the theme of problem-focused coping entails problem solving. Dispositional maladaptive and ineffective coping strategies usually result in frequent or chronic state of hardship and tension (14). This in turn may lead to compromised functioning of the immune system and hence reducing the defense against virulent or opportunistic pathogens $(9,46)$. Extensive research by James Pennebaker and his associates (57) also strongly suggested that coping with stress is facilitated by confronting and working through the threats they produce. This may also explain why problem-focused coping is often associated with high levels of wellbeing (58).

Subjests high in either anxiety trait or depression trait had higher odds for periodontal disease in the present study (Table 8). In other words, subjects who are trait anxious or trait depressive are more vulnerable to periodontal disease as measured by clinical attachment loss. Spielberger (59) advocated the well known distinction between state and trait anxiety (60). State anxiety is viewed as a transient condition of subjective feelings of tension, apprehension and increased autonomic activity, while trait anxiety is viewed as a relatively stable individual proneness to anxiety, or a tendency to respond to situations with characteristic levels of state anxiety. Traditionally, the personality dimension of neuroticism used to be considered as a vulnerability factor for psychological problem (61). Recently, it was suggested that trait anxiety could possibly be a vulnerability factor which predisposes individuals to develop clinical anxiety (34). According to Spielberger (62), people who are high in trait anxiety as measured by the State-Trait Anxiety Inventory (STAI; 63) are more vulnerable to stress and respond to a wider range of situations as dangerous or threatening. 
Findings in the present study appear compatible with existing evidence that high anxiety or depression trait renders the subjects more susceptible to stressful status, more vulnerable in developing stress reactions and in turn adverse effects on immune response resulting in reduced resistance to periodontal disease.

Interesting relationships were found between severity of periodontal attachment loss, job strain and financial strain, coping behaviors, and trait dispositions of anxiety and depression (Table 10). Subjects with job strain or financial strain who used more emotion-focused coping strategies had even more periodontal disease. Adequate coping behaviours, either "low" emotion-focused coping or "high" problem-focused coping, with the chronic job or financial stress resulted in little or no effect on periodontal status. Inadequate coping, evidenced as either "high" emotion-focused coping or "low" problem-focused coping, with the chronic stress lead to more severe periodontal disease. The Erie County study (6) demonstrated the same pattern of interaction between financial strain and coping behaviours. The findings of the present study added further the role of personality traits in modifying the stress reaction. Individuals with more favourable personality dispositions, that is, those with low scores of anxiety trait or depression trait, had no more periodontal tissue destruction, even though they reported high levels of job strain or financial strain. Conversely, those with high levels of job strain or financial strain with less favourable personality dispositions, evidenced as high scores of anxiety trait or depression trait, were found to have even more severe periodontal attachment loss (Table 10). These interactions echo the contemporary theoretical concept of coping strategies and personality dispositions being the mediating factors in the stress process that determine how people react to stressor $(14,19)$. To these ends, the possibility of employing psychological intervention as adjunctive measure in treatment of periodontal disease would probably deserve further evaluation.

Compared to the healthy subjects, there were trends of more severe psychological symptoms of depression in those with more severe attachment loss as measured by the 
SCL-90 with an odds ratio of $1.41(95 \%$ C.I. $=1.17$ - 2.78) (Table 8). Clinical depressive disorder is the affective disorder which has consistently demonstrated immunologic changes $(46,64)$. This provided a possible explanation of depression as a significant risk indicator in periodontal disease. Management of depressive affectivity may need to be assessed and considered in treatment of periodontal disease.

Almost all of the participants in the present study expressed during the debriefing time upon completion of psychological assessments that the questionnaires were very long and they felt rather tired completing them. On average, participants took 25 to 30 minutes to complete all the psychological instruments. Acknowledging the subjects' burden in completing the questionnaires, it also has to be admitted that exploration of psychological components and contribution in physical disease inevitably involves evaluation of a certain number of psychological constructs. Despite these comments from the subjects, the results in the present study remained reliable and valid as discussed earlier.

Whether stress-associated odds of periodontal disease is related to behavioural and/or pathophysiological changes is yet to be determined. Studies directing towards the biochemical and physiological mechanisms by which psychosocial stress contributes to periodontal destruction are needed to establish the biological rationale for this relationship. Another general concern in this area of research has been the clinical significance of stress induced alternations of immune functions. Future research must address the specific association between stress process, diminished immunocompetence and the development of periodontal disease; the magnitude of this association, the temporal contingency and the dose-response relationship should also be explored. Such studies may include assessment of biochemical, neurological, immunological and endocrinological alterations in addition to psychological and behavioural changes. Evaluation of these mechanisms with animal models is deemed necessary and instructive.

Stress management training in general, or the contemporary Cognitive Behavioural 
Therapy in particular, which have been advocated in managing daily living stress, enhancing coping strategies and allowing adaptive adjustment of trait disposition (65) could be potentially adjunctive regimes in treatment of periodontitis subjects with unfavourable psychological background. A longitudinal study on a subgroup of the present study sample has been carried out to further explore and evaluate if intervention focus on stress management enhancement training may serve adjunctive roles in prevention and/or treatment for periodontal disease. Further longitudinal study on a cohort of periodontally healthy subjects, including those with adequate or inadequate coping strategies, with or without significant job or financial strains are recommended to allow a more in-depth analysis of the effects and interaction of these psychosocial factors. Integrated clinical, sociological and molecular based studies are needed for full understanding the role of stress as a contributor to periodontal disease.

\section{Acknowledgements}

We thank the three dental clinics, two dental surgery assistants, two interviewers and the panel of two voluntary dentists, two psychologists and one statistician in assisting smooth running of the study. The work described in this paper was substantially supported by a grant from the Research Grants Council of the Hong Kong Special Administrative Region, China (HKU 7331/00M). 


\section{Reference}

1. Page RC, Kornman KS. The pathogenesis of human periodontitis: an introduction. Periodontol 2000 1997;14:9-11.

2. Grossi SG, Zambon JJ, Ho AW, Koch G, Dunfort RG, Machtei EE, Norderyd OM, Genco R. Assessment of risk for periodontal disease. I. Risk indicators for attachment loss. J Periodontol 1994;65:260-7.

3. Grossi SG, Genco RJ, Machtei EE, Ho AW, Koch G, Dunford R, Zambon JJ, Hausmann E. Assessment of risk for periodontal disease. II. Risk indicators for alveolar bone loss. J Periodontol 1995;66:23-9.

4. Page RC, Offenbacher S, Schroeder HE, Seymour GJ, Kornman KS. Advances in the pathogenesis of periodontitis: summary of developments, clinical implications and future directions. Periodontol 2000 1997;14:216-48.

5. Marcenes WS, Sheiham A. The relationship between work stress and oral health status. Soc Sci Med 1992;35:1511-20.

6. Genco RJ, Ho AW, Grossi SG, Dunford RG, Tedesco LA. Relationship of stress distress and inadequate coping behaviors to periodontal disease. J Periodontol 1999;70:711-23.

7. Cohen LH, Simons RF, Rose SC, McGowan J, Zelson MF. Relationships among negative life events physiological reactivity and health symptomatology. J Human Stress $1986 ; 12: 142-8$.

8. Cooper CL, Faragher EB. Psychosocial stress and breast cancer: the inter-relationship between stress events coping strategies and personality. Psychol Med 1993;23:653-62.

9. Monteiro da Silva AM, Newman HN, Oakley DA. Psychosocial factors in inflammatory periodontal diseases. A review. J Clin Periodontol 1995;22:516-26.

10. Green LW, Tryon WW, Marks B, Juryn J. Periodontal disease as a function of life-events stress. Journal of Human Stress 1986;12:32-6. 
11. Freeman R, Goss S. Stress measures as predictors of periodontal disease-a preliminary communication. Community Dent Oral Epidemiol 1993;21:176-7.

12. Marcenes WS, Croucher R, Sheiham A, Marmot MG. The relationship between self-reported oral symptoms and life-events. Psychology and Health 1993;8:123-4.

13. Moss ME, Beck JD, Kaplan BH, Offenbacher S, Weintraub JA, Koch GG, Genco RJ, Matchei EE, Tedesco LA. Exploratory case-control analysis of psychosocial factors and adult periodontitis. J Periodontol 1996;67:1060-9.

14. Lazarus RS. Stress and emotion: a new synthesis. New York: Springer; 1999.

15. Teng HC, Lee CH, Hung HC, Tsai CC, Chang YY, Yang YH, Lu CT, Yen YY, Wu YM. Lifestyle and psychosocial factors associated with chronic periodontitis in Taiwanese adults. J Periodontol 2003;74:1169-75.

16. Andersen BL, Kiecolt-Blaser JK, Glaser R. A biobehavioral model of cancer stress and disease course. American Psychologist 1994;49:3-12.

17. Walker LG, Johnson VC, Eremin O. Modulation of the immune response to stress by hypnosis and relaxation training in healthy volunteers. A critical review. Contemporary Hypnosis 1993;10:19-27.

18. Genco RJ, Ho AW, Kopman J, Grossi SG, Dunford RG, Tedesco LA. Models to evaluate the role of stress in periodontal disease. Ann Periodontol 1998;3:288-302.

19. Lazarus RS. Toward better research on stress and coping. Am Psychol 2000;55:665-73.

20. Pilgram TK, Hildebolt CF, Yokojama-Crothers N, Dotson M, Cohen SC, Hauser JF, Kardaris E. Relationships between radiographic alveolar bone height and probing attachment level: data from healthy post-menopausal women. J Clin Periodontol 2000;27: 341-6.

21. Brugha. TS, Cragg D. The list of threatening experiences: The reliability and validity of a brief Life Events Questionnaire Acta Psychiarrica Scandinavica 1990;82:77-81. 
22. Holmes TH, Rahe RH. The Social Readjustment Rating Scale. Journal of Psychosomatic Research 1967;11:213-8.

23. McGrath RE, Burkhart BR. Measuring life stress: a comparison of the predictive validity of different scoring systems for the social readjustment rating scale. J Clin Psychol 1983;39:573-81.

24. Pearlin LI, Schooler C. The structure of coping. J Health Soc Beh 1978;19:2-21.

25. Pearlin LI. Status inequality and stress in marriage. Am Sociol Rev 1975;40:344-57.

26. Pearlin LI, Radabaugh CW. Economic strains and the coping functions of alcohol. Am J Sociol 1976;82:652-63.

27. Chan DW. Chinese way of coping questionnaire (English \& Chinese) [CWCQ] (1998). In: Corcoran K, Fischer J, editors. Measures for Clinical Practice: A Sourcebook. 3rd edn, vol. 1. New York: Free Press; 2000. p. 521-3.

28. China Association for Mental Health. Rating scales for Mental Health. Beijing, China: Chinese Mental Health Journal; 1993 (In Chinese).

29. Derogatis LR. SCL-90-R: Administration Scoring and Procedures Manual. 3rd edn. Minneapolis Minn.: National Computer Systems; 1994.

30. Lovibond SH, Lovibond PF. Manual for the Depression Anxiety Stress Scales. 2nd edn. Sydney: Psychology Foundation; 1995.

31. Lovibond PF, Lovibond SH. The structure of negative emotional states: Comparison of the Depression Anxiety Stress Scales (DASS) with the Beck Depression and Anxiety Inventories. Behav Res Ther 1995;33:335-43.

32. Ng SKS, Stouthard MEA, Leung WK. Validation of a Chinese version of Dental Anxiety Inventory. Community Dent Oral Epidemiol 2005;33:107-14.

33. Carver CS, Scheier MF, Weintraub JK. Assessing coping strategies: A theoretically based approach. J Pers Soc Psychol 1989;56:267-83. 
34. Chan CK, Lovibond PF. Expectancy bias in trait anxiety. J Abnorm Psychol 1996;105:637-47.

35. MacCallum RC, Zhang S, Preacher KJ, Rucker DD. On the practice of dichotomization of quantitative variables. Psychol Methods 2002;7:19-40.

36. Hong Kong Census and Statistics Department. 2001 Population Census. Hong Kong: Hong Kong Census and Statistics Department; January 2005. Available at: http://www.info.gov.hk/censtatd/eng/hkstat/facs/01c/01c_index.html.

37. Lo ECM, Schwarz E. Tooth and root conditions in the middle-aged and the elderly in Hong Kong. Community Dent Oral Epidemiol 1994;22:381-5.

38. Holmgren CJ, Corbet EF, Lim LP. Periodontal conditions among the middle-aged and the elderly in Hong Kong. Community Dent Oral Epidemiol 1994;22:396-402.

39. Schwarz E, Lo ECM. Dental health knowledge and attitudes among the middle-aged and the elderly in Hong Kong. Community Dent Oral Epidemiol 1994;22:358-63.

40. Cohen BH, Lea RB. Essentials of Statistics for the Social and Behavioral Sciences. Hoboken NJ: Wiley; 2004.

41. Greenstein G. Contemporary interpretation of probing depth assessments: Diagnostic and therapeutic implications. A literature review. J Periodontol 1997;68:1194-205.

42. Wong KC. Depression and its Related Mood Conditions in Hong Kong. Thesis. Hong Kong: The University of Hong Kong; 1996.

43. Ng SKS, Chau AW, Leung WK. The effect of pre-operative information in relieving anxiety in oral surgery patients. Community Dent Oral Epidemiol. 2004;32:227-35.

44. Carver CS. You want to measure coping but your protocol's too long: Consider the brief COPE. Int J Behav Med 1997;4:92-100.

45. Gardell B. Scandinavian research on stress in working life. Int J Health Serv $1982 ; 12: 31-41$. 
46. Dorian BJ, Garfinkel PE, Keystone EC, Gorezynski R, Darby P, Gardner DM. Occupational stress and immunity. Psychosom Med 1985;47:77, abstr.

47. Gwartney J, Lawson R. Economic Freedom of the World: 2004 Annual Report. Canada: The Fraser Institute National Book Network; 2004.

48. International Institute for Management Development (IMD). The World Competitiveness Yearbook 2004. Lausanne, Switzerland: International Institute for Management Development; 2004.

49. Mercer Human Resource Consulting. Cost of Living 2004. Mercer Human Resource Consulting: January 2005. Available at: http://www.mercerhr.com/costofliving.

50. Linden GJ, Mullally BH, Freeman R. Stress and progression of periodontal disease. J Clin Periodontol 1996;23:675-680.

51. Monteiro da, Silva AM, Oakley DA, Newman HN, Nohl FS, Nohl HM. Psychological factors and adult rapidly progressive periodontitiis. J Clinc Periodontol 1996;23:789-794.

52. Croucher R, Marcenes WS, Torres MC, Hughes F, Sheiham A. The relationship between life-events and periodontitis. A case-control study. J Clin Periodontol 1997;24:39-43.

53. Axtelius B, Soderfeldt B, Nilsson A, Edwardsson S, Attström R. Therapy-resistant periodontitis. Psychosocial characteristics. J Clin Periodontol 1998;25:482-491.

54. Wimmer G, Janda M, Wieselmann-Penkner K, Jakse N, Polansky R, Pertl C. Coping with stress: its influence on periodontal disease. J Periodontol 2002;73:1343-51.

55. Hugoson A, Ljungquist B, Breivik T. The relationship of some negative events and psychological factors to periodontal disease in an adult Swedish population 50 to 80 years of age. J Clin Periodontol 2002;29:247-53. 
56. Vettore MV, Leao AT, Monteiro da, Silva AM, Quintanilha RS, Lamarca GA. The relationship of stress and anxiety with chronic periodontitis. J Clin Periodontol 2003;30:394-402.

57. Pennebaker JW, Colder M, Sharp LK. Accelerating the coping process. J Pers Soc Psychol 1990;58:528-537.

58. Hynes GJ, Callan VJ, Terry DJ, Gallois C. The psychological well-being of infertile women after a failed IVF attempt: the effects of coping. $\mathrm{Br} \mathrm{J}$ Med Psychol 1992;65:269-78.

59. Spielberger CD. Anxiety as an emotional state. In: Spielberger CD, editor. Anxiety: Current Trends in Theory and Research, vol. 1. New York: Academic Press; 1972.

60. Cattell RB, Scheier IH. The Meaning and Measurement of Neuroticism and Anxiety. New York: Ronald Press; 1961.

61. Eysenck MW. Anxiety and Cognition: Theory and research. In: Archer T, Nilsson LG, editors. Aversion Conditioning and Anxiety: Perspectives on Aversively Motivated Behaviour. Hillsdale: Erlbaum; 1989.

62. Spielberger CD. Anxiety cognition and affect: A state-trait perspective. In: Tuma AH, Maser J, editors. Anxiety and Anxiety Disorders. Hillsdale: Erlbaum; 1985.

63. Spielberger CD, Gorsuch RL, Lushene RE. Manual for the State-Trait Anxiety Inventory. Palo Alto CA: Consulting Psychological Press; 1970.

64. Atanackovic D, Kroger H, Serke S, Deter HC. Immune parameters in patients with anxiety or depression during psychotherapy. J Affect Disord 2004;81:201-9.

65. Corey, G. Theory and Practice of Counseling and Psychotherapy, 6th edn. Australia: Brooks/Cole; 2001. 
Table 1. Demographic characteristics of subjects

\begin{tabular}{|c|c|c|c|}
\hline \multirow[b]{2}{*}{ Demographic characteristics } & \multicolumn{2}{|c|}{ Sample } & \multirow{2}{*}{$\begin{array}{c}\text { Population } \\
(\%)\end{array}$} \\
\hline & $n$ & $\%$ & \\
\hline \multicolumn{4}{|l|}{ Gender $^{\mathrm{b}}$} \\
\hline Male & 469 & 46.9 & 48.5 \\
\hline Female & 531 & 53.1 & 51.5 \\
\hline \multicolumn{4}{|l|}{ Age in years ${ }^{b}$} \\
\hline 25 to 34 & 292 & 29.2 & 28.2 \\
\hline 35 to 44 & 355 & 35.5 & 34.6 \\
\hline 45 to 54 & 233 & 23.3 & 24.4 \\
\hline 55 to 64 & 120 & 12.0 & 12.8 \\
\hline \multicolumn{4}{|l|}{ Marital status $^{\mathrm{b}}$} \\
\hline Never married & 350 & 35.0 & 31.9 \\
\hline Married & 550 & 55.0 & 59.4 \\
\hline Separated/divorced & 65 & 6.5 & 2.7 \\
\hline Widowed & 35 & 3.5 & 6.0 \\
\hline \multicolumn{4}{|l|}{ Education $^{\mathrm{b}}$} \\
\hline None/pre-school & 38 & 3.8 & 3.8 \\
\hline Primary & 213 & 21.3 & 21.4 \\
\hline Secondary & 576 & 57.6 & 48.0 \\
\hline Tertiary (non-degree) & 45 & 4.5 & 12.7 \\
\hline University degree or above & 128 & 12.8 & 14.1 \\
\hline \multicolumn{4}{|c|}{ Monthly household income (in Hong Kong Dollars) ${ }^{\mathrm{c}, \mathrm{d}}$} \\
\hline$\leq \$ 4,999$ & 100 & 10.9 & 14.9 \\
\hline$\$ 5,000-\$ 9,999$ & 277 & 30.2 & 29.4 \\
\hline$\$ 10,000-\$ 14,999$ & 236 & 25.7 & 23.6 \\
\hline$\$ 15,000-\$ 19,999$ & 128 & 13.9 & 11.8 \\
\hline$\$ 20,000-\$ 24,999$ & 73 & 8.0 & 8.2 \\
\hline$\$ 25,000-\$ 29,999$ & 32 & 3.5 & 3.8 \\
\hline$\geq \$ 30,000$ & 72 & 7.8 & 8.2 \\
\hline \multicolumn{4}{|l|}{ Time of last dental visit ${ }^{b}$} \\
\hline \multicolumn{4}{|l|}{1 year or less } \\
\hline for check-up and professional cleaning & 249 & 24.9 & \\
\hline for dental problem & 112 & 11.2 & \\
\hline 1 to 3 years & 317 & 31.7 & \\
\hline More than 3 years & 252 & 25.2 & \\
\hline Never visited dentist & 59 & 5.9 & \\
\hline
\end{tabular}


Could not remember

$11 \quad 1.1$

Tooth brushing habit ${ }^{b}$

Three times daily

$15 \quad 1.5$

Twice daily

$\begin{array}{ll}707 & 70.7\end{array}$

Once daily

$263 \quad 26.3$

Brushed occasionally

$\begin{array}{ll}7 & 0.7\end{array}$

Never brushed

$\begin{array}{ll}8 & 0.8\end{array}$

${ }^{\mathrm{a}}$ Population reference is from Hong Kong Census and Statistics Department (36).

${ }^{\mathrm{b}} n=1,000$.

${ }^{c}$ USD $\$ 1.00=$ HKD $\$ 7.80$.

${ }^{\mathrm{d}} n=918 ; 82$ subjects refused to disclose income details. 
Table 2. Prevalence of systemic diseases, smoking, drinking habits, and exposure to occupational hazards in the study sample $(N=1,000)$

\begin{tabular}{|c|c|c|}
\hline & Prevalence $(n)$ & Percentage $(\%)$ \\
\hline \multicolumn{3}{|l|}{ Systemic diseases $^{\mathrm{a}}$} \\
\hline Allergy ${ }^{\mathrm{b}}$ & 110 & 11.0 \\
\hline Diabetes & 62 & 6.2 \\
\hline Hypertension & 77 & 7.7 \\
\hline Cardiovascular & 26 & 2.6 \\
\hline Anaemia & 27 & 2.7 \\
\hline Asthma & 51 & 5.1 \\
\hline Others $^{c}$ & 23 & 2.3 \\
\hline Hepatitis B carrier & 98 & 9.8 \\
\hline \multicolumn{3}{|l|}{ Smoking habit ${ }^{\mathrm{d}}$} \\
\hline None & 860 & 86.0 \\
\hline Very light & 11 & 1.1 \\
\hline Light & 39 & 3.9 \\
\hline Moderate & 35 & 3.5 \\
\hline Heavy & 55 & 5.5 \\
\hline \multicolumn{3}{|l|}{ Drinking frequency } \\
\hline Non-drinker/ex-drinker & 487 & 48.7 \\
\hline Drink less than once a month & 310 & 31.0 \\
\hline Drink 1-3 days a month & 80 & 8.0 \\
\hline Drink 1-3 days a week & 92 & 9.2 \\
\hline Daily drinkers & 31 & 3.1 \\
\hline \multicolumn{3}{|l|}{ Hazard $^{\mathrm{e}}$} \\
\hline Chemical & 80 & 8.0 \\
\hline Asbestos & 2 & 0.2 \\
\hline Radiation & 27 & 2.7 \\
\hline Others & 18 & 1.8 \\
\hline
\end{tabular}

${ }^{a}$ Only systemic diseases of frequency $\geq 0.5 \%$ (5 cases) were listed independently.

${ }^{\mathrm{b}}$ Allergies included nasal (24 subjects), skin (18 subjects), nasal and skin (36 subjects), food (19 subjects), medicine (5 subjects), and others allergies ( 8 subjects).

${ }^{\mathrm{c}}$ Others included angina (4 subjects), arthritis (3 subjects), gout (3 subjects), cancer (2 subjects), cataracts (2 subjects), cirrhosis (2 subjects), hepatitis (2 subjects), renal disease (2 
subjects), thyroid disease (2 subjects), emphysema (1 subject).

${ }^{\mathrm{d}}$ Very light smoker: 0 to 5.2 pack-years, light smoker: 5.3 to 15.0 pack-years, moderate smoker: 15.1 to 30.0 pack-years, heavy smoker: more than 30.0 pack-years (2).

${ }^{\mathrm{e}} \mathrm{A}$ total of 127 subjects (12.7\%) reported positive exposure to occupational hazards. 
Table 3. Dental and periodontal parameters

\begin{tabular}{|c|c|c|c|c|c|c|c|c|c|c|}
\hline & \multicolumn{8}{|c|}{ Age } & \multirow{2}{*}{\multicolumn{2}{|c|}{ Overall $(N=1,000)$}} \\
\hline & \multicolumn{2}{|c|}{$25-34(n=292)$} & \multicolumn{2}{|c|}{$35-44(n=355)^{\mathrm{a}}$} & \multicolumn{2}{|c|}{$45-54(n=233)$} & \multicolumn{2}{|c|}{$55-64(n=120)$} & & \\
\hline no. of teeth $($ mean \pm SD) & \multicolumn{2}{|c|}{$27.4 \pm 3.4$} & \multicolumn{2}{|c|}{$26.3 \pm 4.0$} & \multicolumn{2}{|c|}{$23.8 \pm 5.6$} & \multicolumn{2}{|c|}{$21.4 \pm 7.8$} & \multicolumn{2}{|c|}{$25.5 \pm 5.2$} \\
\hline Teeth distribution & $n$ & $(\%)$ & $n$ & $(\%)$ & $n$ & $(\%)$ & $n$ & $(\%)$ & $n$ & $(\%)$ \\
\hline $1-9$ & 0 & 0.0 & 0 & 0.0 & 7 & 3.0 & 12 & 10.0 & 19 & 1.9 \\
\hline $10-19$ & 7 & 2.4 & 16 & 4.5 & 36 & 15.5 & 33 & 27.5 & 92 & 9.2 \\
\hline $20-32$ & 285 & 97.6 & 339 & 95.5 & 190 & 81.5 & 75 & 62.5 & 889 & 88.9 \\
\hline Mean BOP (\%) & \multicolumn{2}{|c|}{$39.7 \pm 15.9$} & \multicolumn{2}{|c|}{$38.2 \pm 19.6$} & \multicolumn{2}{|c|}{$46.3 \pm 12.2$} & \multicolumn{2}{|c|}{$41.0 \pm 34.2$} & \multicolumn{2}{|c|}{$40.9 \pm 19.8$} \\
\hline Mean $\mathrm{Cl}(\%)$ & \multicolumn{2}{|c|}{$70.7 \pm 10.4$} & \multicolumn{2}{|c|}{$76.0 \pm 13.1$} & \multicolumn{2}{|c|}{$83.5 \pm 11.0$} & \multicolumn{2}{|c|}{$74.1 \pm 11.7$} & \multicolumn{2}{|c|}{$76.0 \pm 12.6$} \\
\hline $\mathrm{CAL}($ mean $\pm \mathrm{SD}$, in $\mathrm{mm})$ & \multicolumn{2}{|c|}{$1.79 \pm 0.66$} & \multicolumn{2}{|c|}{$1.95 \pm 0.85$} & \multicolumn{2}{|c|}{$2.14 \pm 1.16$} & \multicolumn{2}{|c|}{$2.45 \pm 1.13$} & \multicolumn{2}{|c|}{$2.01 \pm 0.94$} \\
\hline
\end{tabular}


Table 4. Prevalence, extent of probing pocket depth, recession and clinical attachment level of the subjects surveyed in ascending order of severity

\begin{tabular}{|c|c|c|c|c|c|c|c|c|}
\hline \multirow[b]{2}{*}{ periodontal variable } & \multirow[b]{2}{*}{$\begin{array}{l}\text { Age } \\
\text { (year) }\end{array}$} & \multirow[b]{2}{*}{$n$} & \multicolumn{2}{|c|}{$\geq 4 \mathrm{~mm}$} & \multicolumn{2}{|c|}{$\geq 6 \mathrm{~mm}$} & \multicolumn{2}{|c|}{$\geq 9 \mathrm{~mm}$} \\
\hline & & & $\begin{array}{l}\text { Prevalence } \\
\text { (\% persons) }\end{array}$ & $\begin{array}{c}\text { Extent } \\
\text { (mean no. } \\
\text { of teeth) }\end{array}$ & $\begin{array}{l}\text { Prevalence } \\
\text { (\% persons) }\end{array}$ & $\begin{array}{c}\text { Extent } \\
\text { (mean no. } \\
\text { of teeth) }\end{array}$ & $\begin{array}{l}\text { Prevalence } \\
\text { (\% persons) }\end{array}$ & $\begin{array}{c}\text { Extent } \\
\text { (mean no. } \\
\text { of teeth) }\end{array}$ \\
\hline \multirow[t]{5}{*}{ Probing depth } & $25-34$ & 292 & 58.9 & 2.1 & 12.7 & 1.2 & 1.7 & 1.6 \\
\hline & $35-44^{\mathrm{a}}$ & 355 & 61.7 & 4.6 & 17.5 & 2.1 & 2.3 & 1.8 \\
\hline & $45-54$ & 233 & 68.2 & 4.7 & 28.8 & 1.8 & 3.4 & 1.1 \\
\hline & $55-64$ & 120 & 59.2 & 4.5 & 20.0 & 2.0 & 1.7 & 1.5 \\
\hline & Overall & 1,000 & 62.1 & 3.9 & 19.0 & 1.8 & 2.3 & 1.5 \\
\hline \multirow[t]{5}{*}{ Recession } & $25-34$ & 292 & 15.4 & 2.1 & 3.8 & 2.6 & 0.0 & 0.0 \\
\hline & $35-44^{\mathrm{a}}$ & 355 & 49.0 & 3.1 & 12.4 & 1.8 & 0.6 & 1.0 \\
\hline & $45-54$ & 233 & 57.1 & 3.0 & 15.5 & 1.7 & 2.6 & 1.2 \\
\hline & $55-64$ & 120 & 60.8 & 3.4 & 25.0 & 2.1 & 4.2 & 1.2 \\
\hline & Overall & 1,000 & 42.5 & 3.0 & 12.1 & 1.9 & 1.3 & 1.2 \\
\hline \multirow[t]{5}{*}{ Clinical attachment level } & $25-34$ & 292 & 61.6 & 4.8 & 19.5 & 1.8 & 2.1 & 6.0 \\
\hline & $35-44^{\mathrm{a}}$ & 355 & 71.8 & 8.0 & 33.8 & 3.2 & 6.8 & 2.5 \\
\hline & $45-54$ & 233 & 79.8 & 8.2 & 45.1 & 3.2 & 14.2 & 1.9 \\
\hline & $55-64$ & 120 & 85.8 & 8.8 & 50.8 & 4.1 & 16.7 & 2.2 \\
\hline & Overall & 1,000 & 72.4 & 7.4 & 34.3 & 3.1 & 8.3 & 2.4 \\
\hline
\end{tabular}

${ }^{\mathrm{a}}$ Similar to corresponding data from a Hong Kong periodontal health survey (38); 35-44 age group i) $\geq 4 \mathrm{~mm}$ (PPD/REC/CAL): $81 / 22 / 74 \%$ 
persons, 7.3/4.1/8.0 teeth; ii) $\geq 6 \mathrm{~mm}$ (PPD/REC/CAL): 20/3/33\% persons, 2.8/2.2/3.3 teeth; iii) $\geq 9 \mathrm{~mm}(\mathrm{PPD} / \mathrm{REC} / \mathrm{CAL}): 2 / 0 / 7 \%$ persons, $1.7 / 1.2 / 2.2$ teeth. 
Table 5. Internal consistency, item-scale correlation and inter-scale correlations between the individual subscales of the various psychological measures ${ }^{\mathrm{a}}$.

\begin{tabular}{|c|c|c|c|c|}
\hline Psychological variables & $\begin{array}{l}\text { No. of } \\
\text { items }\end{array}$ & Cronbach's $\alpha$ & $\begin{array}{l}\text { Item-scale } \\
\text { correlation } \\
\text { coefficients }\end{array}$ & $\begin{array}{c}\text { Correlation } \\
\text { coefficients with } \\
\text { other subscales }\end{array}$ \\
\hline \multicolumn{5}{|l|}{ Daily strains } \\
\hline Job & 19 & 0.94 & $0.78-0.82$ & $0.13-0.20^{\mathrm{b}}$ \\
\hline Financial & 9 & 0.93 & $0.80-0.88$ & $0.12-0.21^{\mathrm{b}}$ \\
\hline Spouse & 16 & 0.87 & $0.65-0.81$ & $0.07-0.17$ \\
\hline Being single & 7 & 0.79 & $0.78-0.85$ & $0.12-0.22$ \\
\hline Children & 33 & 0.89 & $0.81-0.85$ & $0.17-0.22$ \\
\hline Role strain composite & 84 & 0.91 & $0.51-0.79$ & $0.08-0.23$ \\
\hline \multicolumn{5}{|l|}{ SCL-90 } \\
\hline Somatization & 12 & 0.93 & $0.79-0.82$ & $0.11-0.16$ \\
\hline Obsessive-compulsive & 10 & 0.95 & $0.84-0.82$ & $0.15-0.17$ \\
\hline Interpersonal sensitivity & 9 & 0.93 & $0.78-0.83$ & $0.11-0.18$ \\
\hline Depression & 13 & 0.94 & $0.82-0.89$ & $0.14-0.19$ \\
\hline Anxiety & 10 & 0.93 & $0.83-0.86$ & $0.11-0.17$ \\
\hline Hostility & 6 & 0.93 & $0.84-0.84$ & $0.19-0.23$ \\
\hline Phobic sensitivity & 7 & 0.97 & $0.84-0.83$ & $0.20-0.24$ \\
\hline Paranoid ideation & 6 & 0.95 & $0.81-0.83$ & $0.15-0.19$ \\
\hline Psychoticism & 10 & 0.85 & $0.77-0.87$ & $0.11-0.19$ \\
\hline \multicolumn{5}{|l|}{ DASS-S } \\
\hline Depression & 7 & 0.94 & $0.75-0.91$ & $0.31-0.33$ \\
\hline Anxiety & 7 & 0.88 & $0.85-0.93$ & $0.29-0.34$ \\
\hline Stress & 7 & 0.92 & $0.84-0.92$ & $0.32-0.34$ \\
\hline \multicolumn{5}{|l|}{ DASS-T } \\
\hline Depression & 14 & 0.95 & $0.76-0.88$ & $0.31-0.35$ \\
\hline Anxiety & 14 & 0.94 & $0.84-0.89$ & $0.33-0.36$ \\
\hline Stress & 14 & 0.94 & $0.86-0.90$ & $0.29-0.32$ \\
\hline
\end{tabular}

${ }^{a}$ Daily strains $(25,26)$, SCL-90: The Symptom Checklist (29); DASS-S/T: The Depression Anxiety Stress Scale - State/Trait $(30,31)$.

${ }^{b}$ With the exception that the correction coefficient between Job and Financial subscales is $0.41, P<0.05$. 
Table 6. Scores (Mean $\pm \mathrm{SD}$ ) of $\mathrm{COPE}^{\mathrm{a}}$ scale following factor analysis with Varimax rotation.

\begin{tabular}{lc}
\hline COPE & Mean \pm SD \\
\hline Factor 1 - Problem-focused coping & $22.19 \pm 4.67$ \\
Active coping & $5.20 \pm 2.80$ \\
Planning & $5.57 \pm 2.41$ \\
Use of instrumental social support & $5.51 \pm 2.23$ \\
Humour & $5.91 \pm 2.03$ \\
& \\
Factor 2 - Emotion-focused coping & $20.87 \pm 4.15$ \\
Use of emotional support & $4.99 \pm 2.02$ \\
Positive re-interpretation & $5.00 \pm 2.12$ \\
Acceptance & $5.93 \pm 2.01$ \\
Denial & $4.95 \pm 2.94$ \\
& \\
Factor 3 - Less adaptive coping & $8.16 \pm 3.05$ \\
Distraction & $4.32 \pm 2.23$ \\
Focus on venting of emotions & $2.10 \pm 0.52$ \\
Behavioral disengagement & $3.42 \pm 1.82$ \\
\hline
\end{tabular}

${ }^{\mathrm{a} C O P E}$ : The COPE Inventory (33). 
Table 7. Adjusted scores ${ }^{\mathrm{a}}$ (Mean $\pm \mathrm{SE}$ ) of various psychological scales by severity of full mouth mean clinical attachment level $(\mathrm{CAL}), N=$ 1,000

\begin{tabular}{|c|c|c|c|c|c|c|c|c|}
\hline \multirow[b]{2}{*}{ Psychological scale $^{\mathrm{b}}$} & \multicolumn{5}{|c|}{ Clinical attachment level ${ }^{\mathrm{c}}$} & \multirow[b]{2}{*}{ Statistics } & \multirow[b]{2}{*}{ Significance } & \multirow[b]{2}{*}{$\begin{array}{l}\text { Post hoc } \\
\text { analysis }^{\mathrm{d}}\end{array}$} \\
\hline & $\begin{array}{l}\text { Healthy } \\
(n=90)\end{array}$ & $\begin{array}{c}\text { Low } \\
(n=525)\end{array}$ & $\begin{array}{l}\text { Moderate } \\
(n=233)\end{array}$ & $\begin{array}{c}\text { High } \\
(n=101)\end{array}$ & $\begin{array}{l}\text { Severe } \\
(n=51)\end{array}$ & & & \\
\hline LEQ & $0.26 \pm 0.07$ & $0.33 \pm 0.04$ & $0.34 \pm 0.05$ & $0.30 \pm 0.07$ & $0.28 \pm 0.09$ & $F=0.41$ & $P=0.799$ & \\
\hline SRRS & $80.57 \pm 7.42$ & $88.23 \pm 4.44$ & $92.15 \pm 5.36$ & $96.81 \pm 7.11$ & $91.91 \pm 9.19$ & $F=0.95$ & $P=0.434$ & \\
\hline \multicolumn{9}{|l|}{ Daily strains } \\
\hline $\mathrm{Job}^{\mathrm{e}}$ & $2.03 \pm 0.30$ & $2.04 \pm 0.13$ & $2.19 \pm 0.20$ & $2.76 \pm 0.25$ & $2.95 \pm 0.14$ & $F=4.69$ & $P=0.001$ & $1,2,3,4<5$ \\
\hline Financial $^{\mathrm{e}}$ & $1.77 \pm 0.26$ & $1.90 \pm 0.11$ & $2.01 \pm 0.17$ & $2.48 \pm 0.22$ & $2.69 \pm 0.12$ & $F=5.04$ & $P=0.001$ & $1,2,3,4<5$; \\
\hline Spouse & $2.68 \pm 0.22$ & $2.34 \pm 0.11$ & $2.70 \pm 0.11$ & $2.64 \pm 0.18$ & $2.51 \pm 0.21$ & $F=1.85$ & $P=0.117$ & \\
\hline Being single & $2.74 \pm 0.28$ & $2.68 \pm 0.15$ & $2.60 \pm 0.19$ & $2.73 \pm 0.27$ & $2.80 \pm 0.31$ & $F=1.87$ & $P=0.113$ & \\
\hline children & $2.99 \pm 0.44$ & $2.81 \pm 0.25$ & $3.48 \pm 0.40$ & $2.73 \pm 0.52$ & $3.12 \pm 0.34$ & $F=1.13$ & $P=0.340$ & \\
\hline Role strain composite ${ }^{\mathrm{e}}$ & $2.39 \pm 0.25$ & $2.19 \pm 0.10$ & $2.43 \pm 0.16$ & $2.70 \pm 0.21$ & $2.85 \pm 0.12$ & $F=4.17$ & $P=0.002$ & $1,2,3,4<5$; \\
\hline \multicolumn{9}{|l|}{ SCL-90 } \\
\hline Somatization & $3.64 \pm 2.48$ & $7.37 \pm 1.05$ & $7.14 \pm 1.63$ & $7.10 \pm 2.09$ & $9.58 \pm 1.17$ & $F=0.81$ & $P=0.521$ & \\
\hline Obsessive-compulsive & $7.52 \pm 2.44$ & $11.27 \pm 1.03$ & $9.93 \pm 1.60$ & $12.60 \pm 2.05$ & $12.56 \pm 1.16$ & $F=2.08$ & $P=0.081$ & \\
\hline Interpersonal sensitivity & $5.05 \pm 2.06$ & $7.10 \pm 0.87$ & $5.18 \pm 1.35$ & $6.65 \pm 1.73$ & $9.20 \pm 0.98$ & $F=0.83$ & $P=0.507$ & \\
\hline Depression $^{\mathrm{e}}$ & $6.50 \pm 3.07$ & $10.67 \pm 1.29$ & $8.88 \pm 2.01$ & $12.10 \pm 2.58$ & $13.99 \pm 1.45$ & $F=2.43$ & $P=0.046$ & $1,2,3,4<5$; \\
\hline Anxiety & $2.99 \pm 2.41$ & $7.14 \pm 1.01$ & $6.40 \pm 1.58$ & $6.33 \pm 2.02$ & $8.77 \pm 1.14$ & $F=0.67$ & $P=0.613$ & \\
\hline
\end{tabular}


Hostility

Phobic sensitivity

Paranoid ideation

Psychoticism

\section{DASS-S}

Depression $^{\mathrm{e}}$

Anxiety

Stress

\section{DASS-T}

Depression $^{\mathrm{e}}$

Anxiety $^{\mathrm{e}}$

Stress

$$
\begin{aligned}
& 3.02 \pm 1.24 \\
& 1.85 \pm 1.28 \\
& 4.06 \pm 1.34 \\
& 3.32 \pm 2.07
\end{aligned}
$$

\begin{abstract}
$4.35 \pm 0.52$
\end{abstract}
$4.00 \pm 0.81$

$3.15 \pm 1.04$

$4.81 \pm 0.59$

$F=0.82$

$F=1.04$

$F=1.03$

$F=0.85$

$P=0.515$

$P=0.384$

$5.12 \pm 0.56$

$5.76 \pm 0.87$

$4.78+1.36$

$4.82 \pm 1.13$

$5.81 \pm 0.63$

$7.77 \pm 0.98$

$P=0.392$

$P=0.494$
$4.64 \pm 0.96$

$$
5.41 \pm 0.87
$$

$5.57 \pm 1.49$

$9.09 \pm 1.35$

$6.13 \pm 1.91$

$7.77 \pm 1.74$

$10.00 \pm 1.08$

$5.07 \pm 2.06$

$14.81 \pm 2.64$

$13.92 \pm 1.11$

$15.45 \pm 1.73$

$16.15 \pm 2.22$

$8.46 \pm 0.98$

$F=2.50$

$F=2.13$

$P=0.046$

$P=0.075$

$F=0.64 \quad P=0.634$

\section{$1,2<3,4,5$;}

$15.31 \pm 1.25$
$5.28 \pm 1.85$

$6.37 \pm 1.69$

$9.55 \pm 1.04$

$6.85 \pm 0.95$

$8.11 \pm 1.31$

$$
5.22 \pm 1.44
$$

$F=2.53$

$F=2.43$
$P=0.039$

$P=0.047$
$1,2<3<4,5$; $1,2<5$;

$$
13.28 \pm 2.57 \quad 14.33 \pm 1.08 \quad 14.49 \pm 1.68 \quad 14.30 \pm 2.16 \quad 15.10 \pm 1.21 \quad F=0.13 \quad P=0.970
$$

COPE

\begin{tabular}{lcccccccc} 
Problem-focused coping $^{\mathrm{e}}$ & $23.58 \pm 1.76$ & $23.29 \pm 0.74$ & $24.88 \pm 1.15$ & $21.59 \pm 1.48$ & $19.45 \pm 0.83$ & $F=2.55$ & $P=0.038$ & $1,2,3>5 ;$ \\
Emotion-focused coping $^{\mathrm{e}}$ & $20.20 \pm 1.33$ & $20.53 \pm 0.75$ & $19.33 \pm 1.04$ & $22.97 \pm 1.58$ & $22.22 \pm 0.67$ & $F=2.53$ & $P=0.039$ & $1,2<4,5 ;$ \\
Less adaptive coping & $7.32 \pm 1.14$ & $7.97 \pm 0.48$ & $6.80 \pm 0.75$ & $8.04 \pm 0.96$ & $10.24 \pm 0.54$ & $F=1.72$ & $P=0.143$ & \\
\hline
\end{tabular}

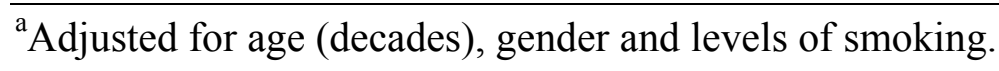

${ }^{b}$ LEQ: The Life Event Questionnaire (21); SRRS: The Social Readjustment Rating Scale (22); Daily strains (25, 26); SCL-90: The Symptom Checklist (29); DASS-S/T: The Depression Anxiety Stress Scale - State/Trait (30, 31); COPE: The COPE Inventory (33).

${ }^{\mathrm{c}} \mathrm{CAL}$ categories: healthy -0 to $1.0 \mathrm{~mm}$; low -1.1 to $2.0 \mathrm{~mm}$; moderate -2.1 to $3.0 \mathrm{~mm}$; high -3.1 to $4.0 \mathrm{~mm}$; and severe - above $4.0 \mathrm{~mm}$ (6). ${ }^{\mathrm{d}}$ Post hoc analysis by Turkey HSD tests, groups 1, 2, 3, 4 and 5 refer to levels of clinical attachment loss from healthy [1] to severe [5].

${ }^{\text {e}}$ Statisitcally significant differences in mean scores between the various severities of clinical attachment loss, $P \leq 0.05$, ANCOVA. 
Table 8. Stepwise ordinal logistic regression analysis of potential risk indicators for clinical attachment levels ${ }^{\mathrm{a}}$.

\begin{tabular}{|c|c|c|}
\hline & Estimated odds ratio ${ }^{b}$ & $95 \%$ confidence interval \\
\hline Heavy Smoker $^{\mathrm{c}}$ & 4.61 & $2.88-5.68$ \\
\hline Age 55-64 & 4.07 & $2.89-5.81$ \\
\hline Age $45-54$ & 3.50 & $2.50-4.92$ \\
\hline Moderate smoker ${ }^{\mathrm{c}}$ & 2.69 & $1.39-4.31$ \\
\hline Light smoker ${ }^{\mathrm{c}}$ & 2.33 & $1.32-3.52$ \\
\hline Age $35-44$ & 2.24 & $1.05-3.87$ \\
\hline Diabetes & 2.15 & $1.31-2.87$ \\
\hline Depression (Trait) & 1.62 & $1.15-2.35$ \\
\hline Anxiety (Trait) & 1.51 & $1.09-2.72$ \\
\hline Job strain & 1.47 & $1.21-2.01$ \\
\hline Depression (SCL-90) & 1.41 & $1.17-2.78$ \\
\hline Financial strain & 1.38 & $1.13-1.71$ \\
\hline Gender (male) & 1.27 & $1.05-1.65$ \\
\hline Emotion-focused coping & 1.21 & $1.09-1.73$ \\
\hline Problem-focused coping & 0.85 & $0.71-0.90$ \\
\hline Allergy & 0.77 & $0.58-0.96$ \\
\hline Education & 0.75 & $0.59-0.91$ \\
\hline
\end{tabular}

${ }^{\mathrm{a}} n=767$; dichotomized clinical attachment levels: $0=$ healthy/low mean CAL categories, 1

$=$ high/severe mean CAL categories; please refer to Table 7 for CAL categories classification.

${ }^{\mathrm{b}}$ Statistically significant $(P<0.05)$.

${ }^{c}$ Light smoker: 5.3 to 15.0 pack-years, moderate smoker: 15.1 to 30.0 pack-years, heavy smoker: more than 30.0 pack-years (2). 
Table 9. Statistics of subjects stratified according to anxiety and depression dispositions, and coping styles ${ }^{\mathrm{a}}$.

\begin{tabular}{lcccc}
\hline & $\begin{array}{c}\text { High } \\
(\text { Mean } \pm \text { SD) }\end{array}$ & $\begin{array}{c}\text { Low } \\
(\text { Mean } \pm \text { SD) }\end{array}$ & t-statistics & significance \\
\hline Depression - Trait & $9.48 \pm 5.07$ & $2.17 \pm 1.09$ & 31.96 & $P<0.001$ \\
Anxiety - Trait & $9.99 \pm 4.32$ & $2.19 \pm 1.91$ & 32.28 & $P<0.001$ \\
Problem-focused coping & $26.19 \pm 1.10$ & $18.20 \pm 3.22$ & 45.89 & $P<0.001$ \\
Emotion-focused coping & $17.51 \pm 2.52$ & $24.24 \pm 2.60$ & 36.46 & $P<0.001$ \\
\hline
\end{tabular}

${ }^{a}$ Subjects (total of 767 , from healthy/low mean CAL or high/severe mean CAL categories) were stratified into "high" and "low" trait depression, trait anxiety, problem-focused coping, or emotion-focused coping groups by median-split (35); trait dispositions detected by The Depression Anxiety Stress Scale - Trait $(30,31)$; coping styles detected by The COPE Inventory (33). 
Table 10. The interaction of trait dispositions and coping styles, with job and financial strains in odds evaluation of periodontal attachment loss ${ }^{\mathrm{a}}$

\begin{tabular}{|c|c|c|c|c|c|c|c|c|c|c|c|c|c|c|c|c|}
\hline \multirow{3}{*}{$\begin{array}{l}\text { Psychological } \\
\text { Scale }^{\mathrm{b}}\end{array}$} & \multicolumn{4}{|c|}{ Depression (Trait) } & \multicolumn{4}{|c|}{ Anxiety (Trait) } & \multicolumn{4}{|c|}{ Problem-focused coping } & \multicolumn{4}{|c|}{ Emotion-focused coping } \\
\hline & \multicolumn{2}{|c|}{ High } & \multicolumn{2}{|c|}{ Low } & \multicolumn{2}{|c|}{ High } & \multicolumn{2}{|c|}{ Low } & \multicolumn{2}{|c|}{ High } & \multicolumn{2}{|c|}{ Low } & \multicolumn{2}{|c|}{ High } & \multicolumn{2}{|c|}{ Low } \\
\hline & O.R. ${ }^{\mathrm{c}}$ & $95 \%$ C.I. & O.R. & $95 \%$ C.I. & O.R. & 95\% C.I. & O.R. & 95\% C.I. & O.R. & 95\% C.I. & O.R. & 95\% C.I. & O.R. & 95\% C.I. & O.R. & $95 \%$ C.I. \\
\hline LEQ & 1.32 & $0.81-2.17$ & 1.18 & $0.59-1.79$ & 1.38 & $0.98-1.77$ & 1.07 & $0.63-1.24$ & 1.45 & $0.76-2.17$ & 2.27 & $0.66-1.83$ & 1.45 & $0.75-2.25$ & 2.39 & $0.68-1.90$ \\
\hline SRRS & 1.56 & $0.52-2.03$ & 0.88 & $0.92-3.11$ & 2.30 & $0.85-1.89$ & 1.12 & $0.88-2.24$ & 1.07 & $0.47-1.93$ & 1.60 & $0.99-3.02$ & 1.22 & $0.43-1.92$ & 1.77 & $0.16-3.09$ \\
\hline \multicolumn{17}{|l|}{ Daily strains } \\
\hline Job & $2.12^{\mathrm{d}}$ & $1.36-3.06$ & 1.77 & $0.35-3.78$ & $2.27^{\mathrm{d}}$ & $1.65-2.98$ & 1.95 & $0.14-3.18$ & 2.15 & $0.28-3.09$ & $2.94^{\mathrm{d}}$ & $2.21-3.88$ & $2.96^{\mathrm{d}}$ & $2.12-3.96$ & 2.10 & $0.23-3.06$ \\
\hline Financial & $1.97^{\mathrm{d}}$ & $1.19-3.21$ & 1.62 & $0.22-2.87$ & $2.03^{\mathrm{d}}$ & $1.69-2.96$ & 1.83 & $0.24-3.06$ & 2.01 & $0.23-3.27$ & $2.33^{\mathrm{d}}$ & $1.68-2.93$ & $2.42^{\mathrm{d}}$ & $1.64-2.93$ & 2.05 & $0.32-3.24$ \\
\hline Spouse & 1.65 & $0.88-2.78$ & 1.28 & $0.78-2.50$ & 1.02 & $0.80-0.96$ & 0.81 & $0.67-1.99$ & 1.35 & $0.87-2.56$ & 1.81 & $0.80-2.83$ & 1.75 & $0.72-2.80$ & 1.41 & $0.93-2.63$ \\
\hline Being single & 1.28 & $0.97-2.81$ & 0.98 & $0.08-1.90$ & 1.57 & $0.92-2.94$ & 1.51 & $0.15-1.34$ & 0.89 & $0.79-1.89$ & 1.15 & $0.31-2.76$ & 1.28 & $0.42-2.67$ & 1.03 & $0.80-1.82$ \\
\hline Children & 1.07 & $0.78-3.11$ & 0.87 & $0.54-1.75$ & 1.99 & $0.59-3.97$ & 1.81 & $0.92-2.91$ & 0.69 & $0.64-1.84$ & 1.01 & $0.72-3.05$ & 1.15 & $0.69-2.95$ & 0.86 & $0.72-1.91$ \\
\hline \multicolumn{17}{|l|}{ Role strain } \\
\hline composite & 1.51 & $0.98-2.33$ & 1.33 & $0.88-2.17$ & 1.83 & $0.56-2.75$ & 1.63 & $0.84-3.29$ & 1.31 & $0.94-2.36$ & 1.42 & $0.96-2.17$ & $1.34^{\mathrm{d}}$ & $0.88-2.38$ & 1.25 & $0.87-2.24$ \\
\hline
\end{tabular}

${ }^{a} n=767$; dichotomized clinical attachment levels: $0=$ healthy/low mean CAL categories, $1=$ high/severe mean CAL categories; please refer to Table 7 for CAL categories classification; subjects were stratified into "high" and "low" trait depression, trait anxiety, problem-focused coping, emotion-focused coping groups by median-split (35); all models were adjusted for age (decades), gender and smoking bLEQ: The Life Event Questionnaire (21); SRRS: The Social Readjustment Rating Scale (22); Daily strains $(25,26)$.

${ }^{\mathrm{c}} \mathrm{O} . \mathrm{R} .=$ odds ratio.

${ }^{\mathrm{d}}$ Statically significant between high and low depression/anxiety trait or coping groups $(P<0.05)$. 